\title{
An Unusual Case of Pedal Swelling
}

\author{
Amit K Sarkar ${ }^{1}$, Pranabananda Pal ${ }^{2}$, Anup K Dutta ${ }^{3}$
}

\begin{abstract}
We present the case of a 40-year-old woman presenting with bilateral asymmetric pedal swelling and abdominal lump. Investigations revealed a retroperitoneal necrotic mass encasing the large vessels along with deep venous thrombosis of bilateral femoral, popliteal, and saphenous veins. There were erosion of lumber vertebra and encroachment of paravertebral muscles.

The extensive spread, vascular involvement, and necrosis on imaging pointed provisionally to a retroperitoneal sarcoma though we lost the patient before histological confirmation could be done.

Keywords: Paravertebral muscle, Retroperitoneal sarcoma, Venous thrombosis.

Bengal Physician Journal (2020): 10.5005/jp-journals-10070-7014
\end{abstract}

\section{Case Description}

A 40-year-old woman with a history of two pregnancy losses presented with acute onset asymmetric swelling, pain, and rubor of both lower limbs for the last 1 week (Fig. 1).

The patient had developed abdominal swelling and pain along with generalized cachexia for the last 7 months.

On examination, there were moderate pallor, poor nutrition, and bilateral asymmetric pedal swelling (right $>$ left). The lower limbs were swollen, tender, and erythematous, and pulses were palpable with loss of jerks and absent plantar response.

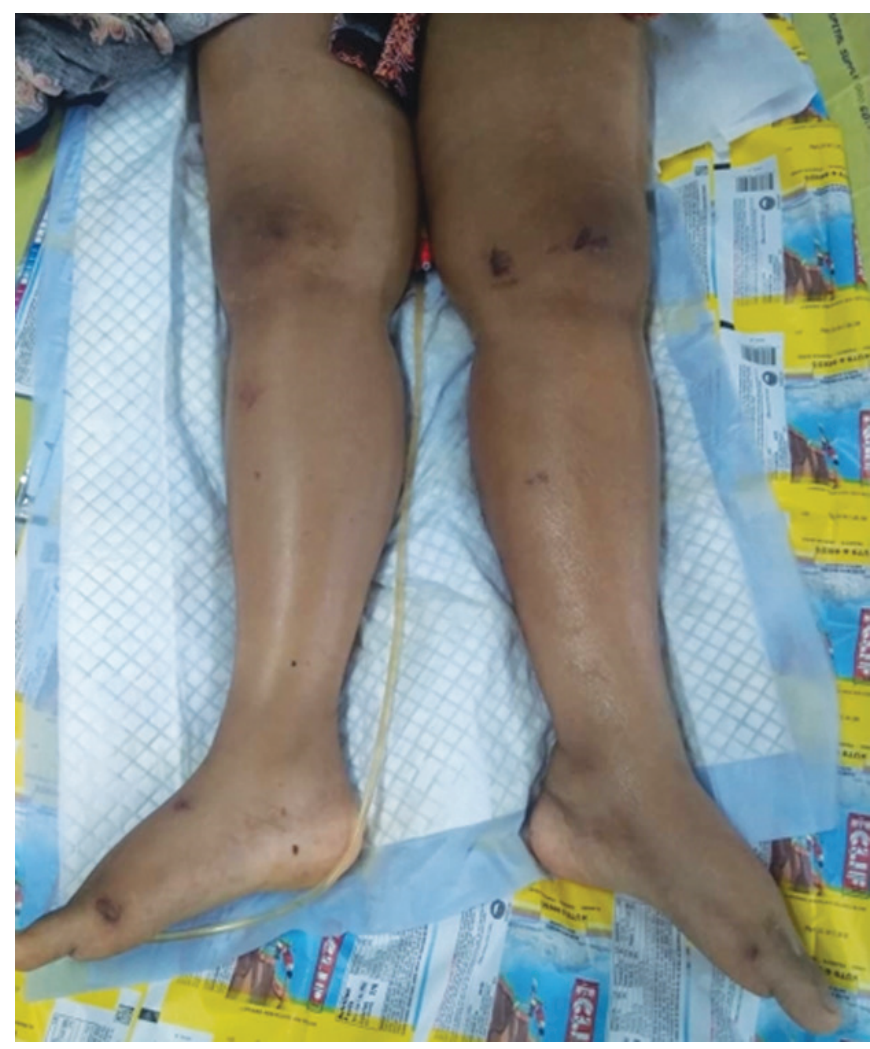

Fig. 1: Bilateral asymmetric pedal swelling

\footnotetext{
${ }^{1-3}$ Department of Medicine, IPGMER and SSKM Hospital, Kolkata, West Bengal, India
}

Corresponding Author: Pranabananda Pal, Department of Medicine, IPGMER and SSKM Hospital, Kolkata, West Bengal, India, Phone: +8240380884, e-mail: rivuc23092006@gmail.com

How to cite this article: Sarkar AK, Pal P, Dutta AK. An Unusual Case of Pedal Swelling. Bengal Physician Journal 2020;7(2):43-44.

Source of support: Nil

Conflict of interest: None
Abdominal examination revealed hard nontender fixed lump extending over almost the whole of the abdomen. Knee elbow position revealed a retroperitoneal location.

The investigations were as follows:

Blood picture revealed moderate normocytic normochromic anemia with no abnormal cells, while biochemistry was noncontributory.

USG Doppler revealed DVT in B/L popliteal vein, B/L femoral vein, and $B / L$ saphenous vein. The thrombus was seen to extend in IVC up to $8 \mathrm{~cm}$ away from the junction of right atrium. An abdominopelvic mass was seen to originate from the left adnexa.

CECT W/A (Figs 2 to 4) revealed an abdominopelvic mass with necrotic areas encasing the aorta, IVC, and B/L common iliac vein. The mass eroded into the lumbar vertebra and paravertebral muscles at the level of L5-S1.

Extensive thrombus was seen in IVC extending into the right renal vein. The left kidney showed hydronephrotic change with dilated pelvicalyceal system (Fig. 5).

Multiple retroperitoneal pre- and para-aortic lymph nodes were also seen.

Unfortunately, the patient succumbed before a biopsy could be performed.

A provisional diagnosis of retroperitoneal sarcoma was suggested by the radiologist based on retroperitoneal location, massive size, encasement of great vessels, and internal necrosis patterns though histological confirmation was definitely warranted.

(c) The Author(s). 2020 Open Access This article is distributed under the terms of the Creative Commons Attribution 4.0 International License (https:// creativecommons.org/licenses/by-nc/4.0/), which permits unrestricted use, distribution, and non-commercial reproduction in any medium, provided you give appropriate credit to the original author(s) and the source, provide a link to the Creative Commons license, and indicate if changes were made. The Creative Commons Public Domain Dedication waiver (http://creativecommons.org/publicdomain/zero/1.0/) applies to the data made available in this article, unless otherwise stated. 


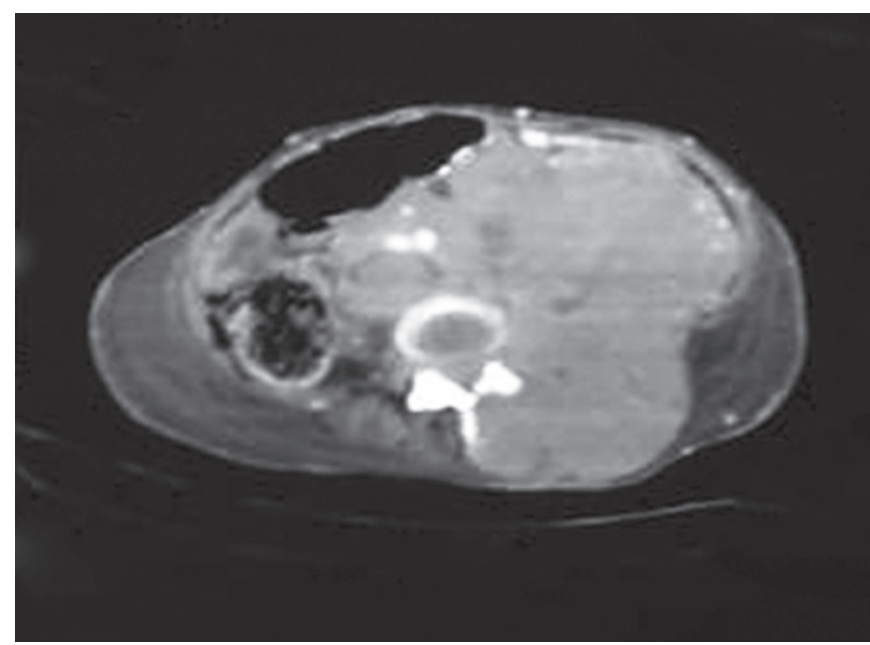

Fig. 2: Abdominopelvic mass with necrotic areas encasing the IVC, aorta, and $\mathrm{B} / \mathrm{L}$ common iliac veins and encroaching into paravertebral muscles

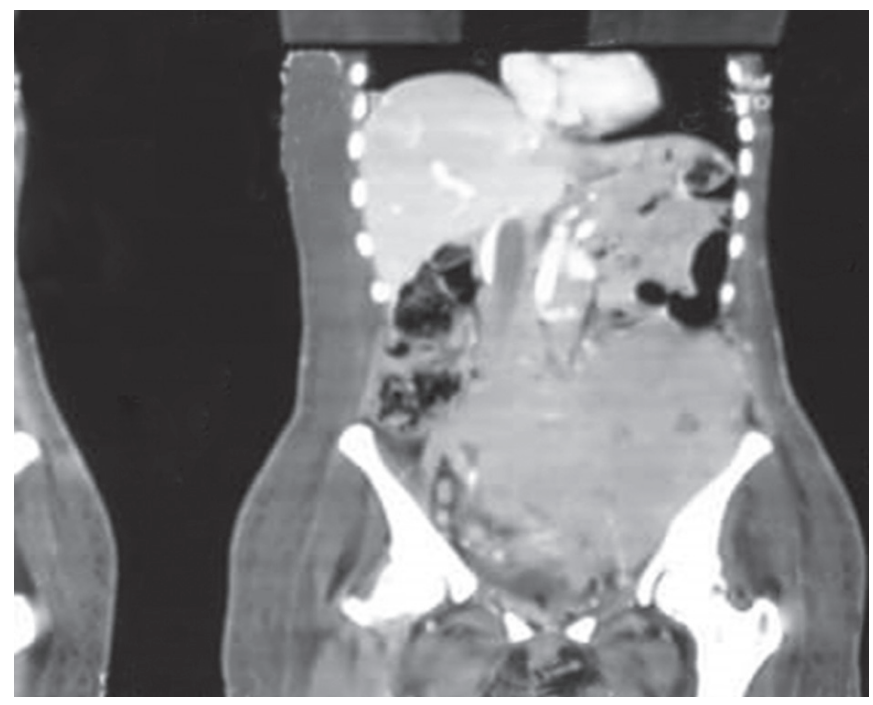

Fig. 3: Large abdominopelvic mass displacing the gut to the opposite side

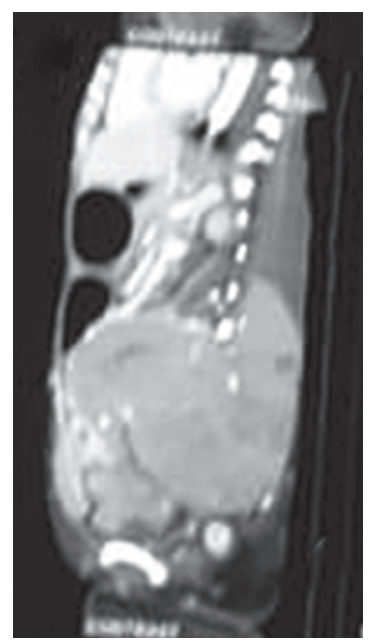

Fig. 4: Abdominopelvic mass with necrotic areas engulfing the vertebra and paravertebral muscles

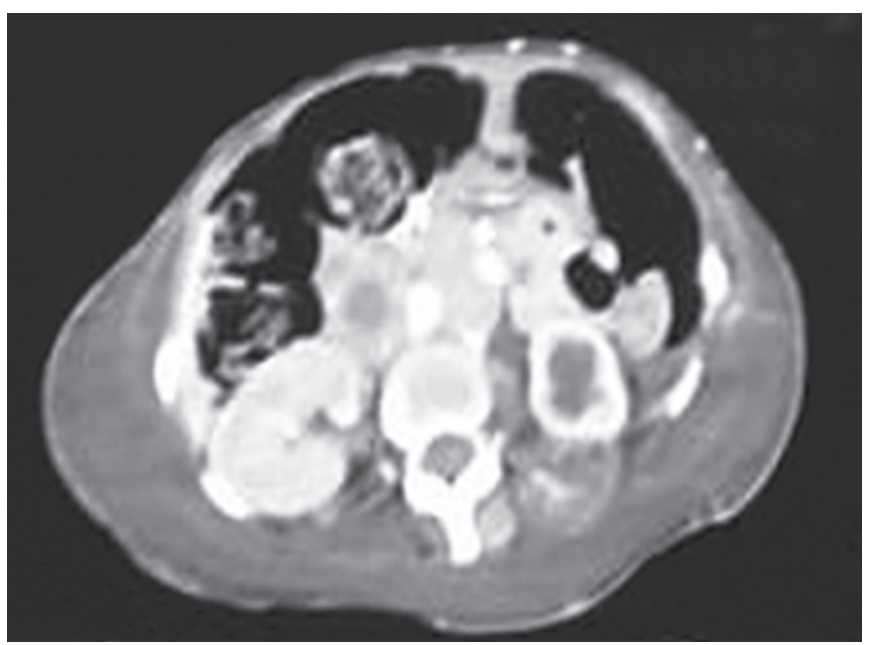

Fig. 5: Left-sided hydronephrotic change with dilated pelvicalyceal system

\section{Discussion}

Retroperitoneal masses can arise from any of the retroperitoneal organs or structure such as kidneys, adrenals, pancreas, duodenum, descending colon, IVC, aorta, nerves, mesodermal and lymphoid tissues, as well as germ cells. ${ }^{1}$

Retroperitoneal sarcoma is a rare tumor with an incidence of 0.5 to $1 / 1$ lakh, $70-80 \%$ of which is malignant. They are large aggressive tumors and often encase big vessel and adjacent organs. The commonest tumors are liposarcoma (33\%) and leiomyosarcoma (29\%). Confirmation requires biopsy through lateral or posterior approach to avoid peritoneal seeding. ${ }^{2}$

In our patient, the presence of extensive necrosis and the involvement of contiguous vessels point to a diagnosis of leiomyosarcoma though a histological confirmation was mandatory before giving therapy. ${ }^{3,4}$

Complete resection of tumor is the mainstay, but the use of neoadjuvant radiotherapy or chemotherapy may be individualistic in cases with high risk of recurrence. ${ }^{5,6}$

\section{References}

1. McGrath P. Retroperitoneal sarcomas. Semin Surg Oncol 1994;10:364-368. DOI: 10.1002/ssu.2980100509.

2. Papanicolaou N, Yoder IC, Lee MJ. Primary retroperitoneal neoplasms: how close can we come in making the correct diagnosis. Urol Radio 1992;14:221-228. DOI: 10.1007/BF02926936.

3. Arca MJ, Sondak VK, Chang AE. Diagnostic procedures and pretreatment evaluation of soft tissue sarcomas. Semin Surg Oncol 1994;10:323-331. DOI: 10.1002/ssu.2980100504.

4. Blum U, Wildanger $G$, Winfuhr $M$, et al. Preoperative $C T$ and MR imaging of inferior vena cava leiomyosarcoma. Eur J Radiol 1995;20:23-27. DOI: 10.1016/0720-048x(95)00608-s.

5. Pisters PWT, Ballo MT, Patel SR. Preoperative chemoradiation treatment strategies for localized sarcoma. Ann Surg Oncol 2002;9:535-542. DOI: 10.1007/BF02573888.

6. Gupta AK, Cohan RH, Francis IR, et al. Patterns of recurrent retroperitoneal sarcomas. AJR 2000;174:1025-1030. DOI: 10.2214/ ajr.174.4.1741025 